\title{
The association between rotating shift work and increased occupational stress in nurses
}

\author{
Pei-Chen LiN ${ }^{1}$, Chung-Hey Chen ${ }^{2,3}$, Shung-Mei PaN ${ }^{4,5}$, Yao-Mei CheN ${ }^{3,6}$, \\ Chih-Hong PAN ${ }^{7}$, Hsin-Chia Hung ${ }^{8}$ and Ming-Tsang Wu $\mathrm{Wu}^{1,9,10}$
}

${ }^{1}$ Department of Public Health, College of Health Sciences, Kaohsiung Medical University, Taiwan, ${ }^{2}$ Institute of Allied Health Sciences \& Department of Nursing, National Cheng Kung University, Taiwan, ${ }^{3}$ College of Nursing, Kaohsiung Medical University, Taiwan, ${ }^{4}$ Department of Nursing, Kaohsiung Medical University Hospital, Kaohsiung Medical University, Taiwan, ${ }^{5}$ Department of Nursing, Kaohsiung Municipal Ta-Tung Hospital, Taiwan, ${ }^{6}$ Department of Nursing, Kaohsiung Municipal Hsiao-Kang Hospital, Taiwan, ${ }^{7}$ Institute of Occupational Safety and Health, Council of Labor Affairs, Executive Yuan, Taiwan, ${ }^{8}$ Department of Nursing, College of Health and Nursing, Meiho University, Taiwan, ${ }^{9}$ Department of Family Medicine, Kaohsiung Medical University Hospital, Kaohsiung Medical University, Taiwan and ${ }^{10}$ Center of Environmental and Occupational Medicine, Kaohsiung Municipal Hsiao-Kang Hospital, Taiwan

\begin{abstract}
The association between rotating shift work and increased occupational stress in nurses: Pei-Chen LiN, et al. Department of Public Health, College of Health Sciences, Kaohsiung Medical University, Taiwan-Purpose: The aim of this study was to investigate whether rotating shift work increases occupational stress in nurses. Methods: This study measured shift work scheduling and occupational stress by using the Effort-Reward Imbalance model with selfreported questionnaires in a sample of 654 female nurses. Results: Overcommitment risk was higher in nurses who worked rotating shifts than in those who worked day/non-night shifts (OR, 2.16; 95\% Cl, 1.03-4.66). However, an effort/reward imbalance was not directly associated with work schedules (OR, 1.88; $95 \% \mathrm{Cl}, 0.87-4.35)$. Among nurses working rotation rotating shifts, those who had 2 days off after their most recent night shifts showed an alleviated risk of overcommitment (OR, 0.52; 95\% Cl, 0.32-0.82), but those who had worked for at least one series of 7 consecutive work days per month had an increased risk of effort/reward imbalance (OR, 2.75; 95\% Cl, 1.69-4.48). Additionally, those who had little or no participation in planning working hours and shift scheduling and worked overtime at least three times per week during the preceding 2 months tended to have high stress. Conclusions: The
\end{abstract}

Received Dec 15, 2013; Accepted Jun 3, 2014

Published online in J-STAGE May 8, 2014

Correspondence to: M.-T. Wu, Department of Family Medicine, Kaohsiung Medical University Hospital, 100 Shih-Chuan 1st Road, Kaohsiung, Taiwan (e-mail: $960021 @$ @ms.kmuh.org.tw)/H.-C. Hung, Department of Nursing, Meiho University, 23, Pingguang Rd, PingTung, Taiwan (e-mail: hhung2006@gmail.com) nurses who worked rotating shifts tended to experience work-related stress, but their stress levels improved if they had at least 2 days off after their most recent night shift and if they were not scheduled to work 7 consecutive days. These empirical data can be used to optimize work schedules for nurses to alleviate work stress.

(J Occup Health 2015; 57: 307-315)

Key words: Effort-reward imbalance, Nurses, Overcommitment, Shift work, Stress

Stress levels among professional nurses have increased in recent years due to the demands of clinical nursing. Previous studies have shown that work demands and stress are associated with adverse mental health such as emotional exhaustion ${ }^{1)}$, depressive disorder ${ }^{2,3)}$ and fatigue ${ }^{4,5)}$, which result in sleep problems and sickness absence ${ }^{1)}$. Stress systems in the body, like the sympathetic-adrenomedullary system and the hypothalamic-pituitary-adrenocortical axis, start working, using adapted processes as the stress attracting ${ }^{6}$, and exhaustion tend to result from longterm exposure.

The nature of the nursing profession inevitably requires 24-hour shift work, and the negative effect of working a night shift is an important occupational hazard. Some previous studies have shown that, compared with nurses who worked day shifts, those who worked rotating shifts or night shifts were more likely to have adverse physical and psychological health effects ${ }^{7,8)}$. Since nurses working shift work have to face and adjust to desynchronization 
between their circadian rhythm and the external environment over the long term, they could suffer stress due to an incomplete adjustment process in the body. Therefore, work stress is an important intermediate factor between shift work and adverse physical and psychological health effects.

Because nurses suffering from mental health problems due to shift work and work stress can adversely affect patient safety ${ }^{9,10)}$, it is important to arrange shift schedules effectively to attenuate the effects of rotating shift work and stress. Although the association between health effects and shift work schedules has been studied, there is still a lack of evidencebased information on the relationship with work stress and rotating shift work schedules. The current working environment among Taiwanese nurses is not conducive to good mental health ${ }^{11}$. Thus, the aims of our research were: (1) to determine the relationship between rotating shift work and work stress in Taiwanese nurses and (2) to determine the optimal characteristics of a work schedule arrangement in order to attenuate the detrimental effects of work stress among nurses working rotating shifts.

\section{Materials and Methods}

\section{Study population}

The population of this study consisted of nurses who had participated in a previous study ${ }^{12}$. In brief, during July to October 2005, 1,486 nurses aged 20 to 45 years old responded to a self-administrated structured questionnaire; these nurses included 456 female nurses recruited from seven hospitals (two medical centers and five regional/district hospitals) and 1,030 nurses of other institutions recruited through the Kaohsiung City and County Nurses Associations ${ }^{12}$.

During April and November 2006, a second questionnaire with additional questions containing the items of the Effort-Reward Imbalance (ERI) model were sent to the nurses, and 799 nurses responded to this investigation. Only the information from the second survey was explored in this study. Therefore, this study had a cross-sectional study design. The study was approved by the Kaohsiung Nursing Association and by the Internal Review Board of Kaohsiung Medical University Hospital (KMUHIRB-94068).

\section{Measurement}

The questionnaire in this study included demographic variables, shift work arrangement and work stress as measured by Effort Reward Imbalance (ERI) model.

\section{Demographic variables}

The demographic factors included age, married status, job title, hospital unit type and hospital grade. These were not only potential factors associated with work stress but also identifying criteria for a change of work environment. Job title was categorized as either nurse or supervisor. Hospital unit type was categorized as intensive care unit (ICU)/emergency room (ER)/operating room (OR), acute ward, outpatient department, chronic ward, public health unit/ school and administration. Hospital grade was classified as medical center, regional/district hospital, clinic/ nursing home and public health institution.

\section{Shift work schedule arrangement and workload}

Shift work was split into three main groups: day shifts, non-night shifts and rotating shifts. A non-night shift was a shift ending before midnight. A rotating shift was defined as a work schedule that included the day shift (from 8 a.m. to 4 p.m.), evening shift (from 4 p.m. to 12 midnight or from 2 p.m. to 10 p.m.) and night shift (from 12 midnight to 8 a.m.) in some kind of rotation ${ }^{12)}$. Nurses who worked a rotating shift system were asked the following further questions about their work schedules: (1) How frequently did your shift change in the last 2 months? (e.g., day shift switched to evening or night shift) (2) How many days off did you receive when you switched from the night shift to other shifts? (3) In the last 2 months, how many night shifts did you work? (4) In the last 2 months, how many times did you work 7 consecutive days per month?

In order to evaluate the working conditions, the respondents were also asked "How many days per week, on average, did you work overtime in the last 2 months?" They further rated their participation in planning working hours in terms of arranging shift schedules (as none, less, moderate, high). Overtime was defined as at least 0.5 working hours in addition to a regular work schedule, excluding face-to-face communications associated with handover of patients to nursing personnel in the following shift.

\section{Effort reward imbalance model}

This study used the ERI model to obtain a selfreported measure of work stress ${ }^{13,14)}$. This model is based on the reciprocity exchange in occupational life. According to the model, effort at work is a cost that is part of a socially organized exchange process to which society at large contributes in terms of reward. The social reward consists of money, self-esteem and career opportunities for the working population ${ }^{14)}$. Two kinds of effort at work are identified: extrinsic and intrinsic effort. The source of extrinsic effort is the demands of the work environment. Workers therefore make an extrinsic effort when they expend energy to try to meet and address those demands. 
The source of intrinsic effort, commitment, is the motivation of an individual worker in a demand situation, which can lead to overcommitment, when the worker asks too much of themselves in order to meet the demands. Overcommitment, a kind of coping, is not only critical enough to result in emotional exhaustion but also exacerbates the negative effects of the effort reward imbalance ${ }^{14,15)}$. Therefore, Siegrist proposed that the lack of reciprocity between "cost", either extrinsic or intrinsic effort, and "gain" (reward), such as is found in a high-cost, low-gain condition, results in a state emotional distress that can cause adverse health problems ${ }^{14)}$.

The Chinese version of the standardized questionnaire for the ERI model measures 23 items on a Likert-type scale ${ }^{16)}$. Two subscales, one for effort and one for reward, were used to measure effort/reward imbalance. Effort is measured by six items related to the demanding aspects of the work environment. Reward comprised 11 items and included subscales for self-esteem (appreciation and support from supervisors and colleagues; five items), social status control (poor promotion prospects, status inconsistency, forced mobility and job insecurity; five items), and financial rewards (adequacy of salary; one item). For each scale, scores of reversed items were reordered so that the items were all measured in the same direction. The effort/reward imbalance was then quantified by the ratio of effort (numerator) and reward (denominator) and qualified by the number of items. An imbalance between effort and reward at work was defied as a ratio larger than one ${ }^{17)}$. Commitment to work, as also known as intrinsic effort, was assessed by asking respondents to indicate their agreement with six statements using a four-point scale from 1 to 4. Overcommitment at work was indicated by a total score in the upper tertile of the possible maximum $^{16,18)}$. In this study, Cronbach alpha values of the ERI model, which test for internal consistency, were 0.86 for "effort", 0.85 for "reward", and 0.77 for "overcommitment".

\section{Data analysis}

The results of the first investigation were used to classify the work shift of the participants into day/ non-night or rotating shifts. In addition to demographic variables, the chi-square test and analysis of variance test were used to compare the three components of the ERI model, commitment, effort and reward. The chi-square test was used for separate comparisons of the two groups in terms of the effect of the shift type on effort/reward imbalance and overcommitment as dichotomous variables. Logistic regression analysis was also used to adjust for potential confounding factors including demographic vari- ables that significantly differed between two groups in the univariate analysis, including age, marital status, job title, hospital grade and unit type. For the missing data, we created another category for particular variables such as age in the logistic regression analysis.

Of the nurses who worked a rotating shift, the values (percentages) and crude odds ratios for effort/reward imbalance and overcommitment were dichotomized to describe the shift work schedule arrangement and workload variables. In the rotating shift group, unit type was classified according to workplace characteristics as ICU/OR/ER, acute ward and chronic ward. Hospital grade was classified as medical center, regional/district hospital or clinic/nursing home. Logistic regression models were further performed to examine for potential confounders. Data were analyzed using JMP for Windows version 9.0; a two-sided $p$ value less than 0.05 was considered statistically significant.

\section{Results}

Out of the initial respondents, 26 stopped participating, 44 changed jobs, 35 did not provide information required for the ERI model and 40 stopped working on a shift schedule, leaving 654 participants. These nurses all worked full-time, their mean age was 31.1 years, and $63.3 \%$ worked rotating shifts. Of the nurses who worked rotating shifts, over half $(64.1 \%)$ were 30 years of age or younger and over half $(62.8 \%)$ were single. The work environment of the rotating shift workers was significantly different from that of day/non-night shift workers in terms of unit and hospital types (Table 1).

The nurses working rotating shifts had significantly worse ERI scores, including overcommitment, effort and reward, compared with nurses who worked day/ non-night shifts (Table 1). Overall, 32.6 and $48.3 \%$ of participants had an effort/reward imbalance and high overcommitment. This percentage was higher among nurses who worked rotating shifts than those who worked day/non-night shifts (40.3 and 52.4\%) (Table 2). After adjusting for age, married status, job title, hospital grade and unit type, nurses who worked rotating shifts had a 2.16-fold (95\% CI=1.03-4.66) higher risk of overcommitment than nurses who worked day/non-night shifts.

The 414 rotating shift nurses also showed an aggravated effort/reward imbalance if they had worked at least one series of 7 consecutive work days per month in the last 2 months $(\mathrm{OR}=2.75,95 \% \mathrm{CI}=1.69-4.48)$ compared with those who did not (Table 3). We also found that they had a 1.89 -fold (95\% CI=1.16-3.12) higher risk of overcommitment than those who did not (Table 4). However, nurses who received at least 
Table 1. Characteristics of the sample population $(\mathrm{N}=654)$

\begin{tabular}{|c|c|c|c|c|c|c|c|}
\hline & \multicolumn{3}{|c|}{ Day/non-night shift } & \multicolumn{3}{|c|}{ Rotating shift } & \multirow{2}{*}{$p$-value } \\
\hline & $\mathrm{N}=240$ & $\%$ & Mean \pm SD & $\mathrm{N}=414$ & $\%$ & Mean \pm SD & \\
\hline Age (years) & & & & & & & $<0.0001$ \\
\hline $21-25$ & 21 & 8.8 & & 97 & 24.1 & & \\
\hline $26-30$ & 61 & 25.4 & & 161 & 40.0 & & \\
\hline $31-35$ & 58 & 24.2 & & 84 & 20.8 & & \\
\hline$>35$ & 100 & 41.7 & & 61 & 15.1 & & \\
\hline Missing & & & & 11 & & & \\
\hline Marital status & & & & & & & $<0.0001$ \\
\hline Single & 74 & 30.8 & & 260 & 62.8 & & \\
\hline Married & 166 & 69.2 & & 154 & 37.2 & & \\
\hline Job tenure (years) & & & & & & & $<0.0001$ \\
\hline$<5$ & 26 & 10.8 & & 138 & 33.3 & & \\
\hline 5 to $<10$ & 63 & 26.3 & & 134 & 32.4 & & \\
\hline$\geq 10$ & 151 & 62.9 & & 142 & 34.3 & & \\
\hline Job title & & & & & & & - \\
\hline Nurses & 200 & 83.3 & & 414 & 100.0 & & \\
\hline Supervisor & 40 & 16.7 & & 0 & 0.0 & & \\
\hline Unit type & & & & & & & $<0.0001$ \\
\hline ICU/OR/ER & 9 & 3.8 & & 152 & 36.7 & & \\
\hline Acute ward & 23 & 9.6 & & 228 & 55.1 & & \\
\hline OPD & 119 & 49.6 & & 0 & 0 & & \\
\hline Chronic ward* & 3 & 1.3 & & 34 & 8.2 & & \\
\hline Public/ school & 37 & 15.4 & & 0 & 0 & & \\
\hline Administration & 49 & 20.4 & & 0 & 0 & & \\
\hline Hospital type & & & & & & & $<0.0001$ \\
\hline Medical center & 57 & 23.8 & & 208 & 50.2 & & \\
\hline Regional/district & 64 & 26.7 & & 175 & 42.3 & & \\
\hline Clinic $\# /$ nursing home & 83 & 34.6 & & 31 & 7.5 & & \\
\hline Public & 36 & 15.0 & & 0 & 0 & & \\
\hline \multicolumn{8}{|l|}{ ERI model } \\
\hline Effort & & & $16.69 \pm 5.45$ & & & $20.05 \pm 5.15$ & $<0.0001$ \\
\hline Reward & & & $43.65 \pm 8.46$ & & & $40.83 \pm 9.35$ & 0.0001 \\
\hline Overcommitment & & & $15.89 \pm 3.04$ & & & $16.70 \pm 2.84$ & 0.006 \\
\hline
\end{tabular}

*Nursing home, respiratory care ward. "Postnatal care, local medical department, hemodialysis center. ICU, intensive care unit type; OR, operating room; ER, emergency room; OPD, outpatient department.

Table 2. Adjusted odds ratio (AOR) of effort/reward imbalance and overcommitment among 654 nurses with shift status

\begin{tabular}{|c|c|c|c|c|c|c|c|c|c|c|}
\hline & \multicolumn{5}{|c|}{ Effort/reward Imbalance } & \multicolumn{5}{|c|}{ Overcommitment } \\
\hline & $\begin{array}{l}\text { Ratio } \leq 1 \\
\mathrm{~N}(\%)\end{array}$ & $\begin{array}{c}\text { Ratio>1 } \\
\mathrm{N}(\%)\end{array}$ & $p$-value ${ }^{\dagger}$ & OR & $\mathrm{AOR}^{*}$ & $\begin{array}{c}\text { Low } \\
\text { N (\%) }\end{array}$ & $\begin{array}{l}\text { High } \\
\text { N (\%) }\end{array}$ & $p$-value ${ }^{\dagger}$ & OR & $\mathrm{AOR}^{*}$ \\
\hline Shift status & & & $<0.0001$ & & & & & 0.0059 & & \\
\hline Day/ non-night shift & $194(80.8)$ & $46(19.2)$ & & 1 & 1 & $141(58.8)$ & $99(41.3)$ & & 1 & 1 \\
\hline Rotating shift & $247(59.7)$ & $167(40.3)$ & & $\begin{array}{c}2.85 \\
(1.97-4.19)\end{array}$ & $\begin{array}{c}1.88 \\
(0.87-4.35)\end{array}$ & $197(47.6)$ & $217(52.4)$ & & $\begin{array}{c}1.7 \\
(1.14-2.17)\end{array}$ & $\begin{array}{c}2.16 \\
(1.03-4.66)\end{array}$ \\
\hline
\end{tabular}

*AOR: adjusted age, marital status, job title, unit type and hospital type. ${ }^{\dagger} p$-value for $\mathrm{X}^{2}$-statistic in the crude analysis. 
Table 3. Adjusted odds ratio (AOR) of the effort/reward imbalance ratio in the ERI model under the rotating shift arrangement among 414 nurses working rotating shifts

\begin{tabular}{|c|c|c|c|c|c|}
\hline & \multicolumn{5}{|c|}{ Effort/Reward Imbalance } \\
\hline & $\begin{array}{l}\text { Ratio } \leq 1 \\
\mathrm{~N}(\%)\end{array}$ & $\begin{array}{l}\text { Ratio }>1 \\
\mathrm{~N}(\%)\end{array}$ & $p$-value ${ }^{\dagger}$ & OR & $\mathrm{AOR}^{*}$ \\
\hline Frequency of shift change & & & 0.1338 & & \\
\hline$<$ l week & $135(58.2)$ & $97(41.8)$ & & 1 & 1 \\
\hline 1 week to $<1$ month & $61(68.5)$ & $28(31.5)$ & & $0.64(0.38-1.06)$ & $0.62(0.36-1.04)$ \\
\hline$\geq 1$ month & $51(54.8)$ & $42(45.2)$ & & $1.15(0.70-1.86)$ & $1.09(0.65-1.82)$ \\
\hline Cumulative night shift days & & & 0.7820 & & \\
\hline 0 to $<7$ days & $104(57.8)$ & $76(42.2)$ & & 1 & 1 \\
\hline 7 to 14 days & $80(61.5)$ & $50(38.5)$ & & $0.86(0.54-1.35)$ & $0.88(0.55-1.42)$ \\
\hline$>14$ days & $63(60.6)$ & $41(39.4)$ & & $0.89(0.54-1.45)$ & $0.87(0.52-1.46)$ \\
\hline Days off after the last night shift & & & 0.0803 & & \\
\hline 1 day & $178(57.2)$ & $133(42.8)$ & & 1 & 1 \\
\hline 2 days & $69(67.0)$ & $34(33.0)$ & & $0.66(0.41-1.05)$ & $0.63(0.39-1.02)$ \\
\hline 7 consecutive work days & & & 0.0007 & & \\
\hline No & $160(65.0)$ & $85(50.9)$ & & 1 & 1 \\
\hline$<1$ time/month & $40(63.5)$ & $23(36.5)$ & & $1.08(0.60-1.91)$ & $1.17(0.63-2.11)$ \\
\hline at least 1 time /month & $46(43.8)$ & $59(56.2)$ & & $2.41(1.52-0.87)$ & $2.75(1.69-4.48)$ \\
\hline Overtime/week & & & 0.0077 & & \\
\hline None & $43(74.1)$ & 15 (25.9) & & 1 & 1 \\
\hline$<3$ days/week & $75(64.7)$ & $41(35.3)$ & & $1.57(0.79-3.22)$ & $1.67(0.83-3.46)$ \\
\hline$\geq 3$ days/week & $129(53.8)$ & $111(46.3)$ & & $2.47(1.33-4.81)$ & $2.65(1.40-5.27)$ \\
\hline $\begin{array}{l}\text { Participation in planning } \\
\text { working hours and scheduling }\end{array}$ & & & $<0.0001$ & & \\
\hline High & $86(68.3)$ & $40(31.8)$ & & 1 & 1 \\
\hline Moderate & $130(65.7)$ & $68(34.3)$ & & $1.12(0.70-1.82)$ & $1.11(0.69-1.82)$ \\
\hline None to low & $31(34.4)$ & $59(65.6)$ & & $4.09(2.32-7.34)$ & $4.00(2.25-7.25)$ \\
\hline
\end{tabular}

OR, odds ratio; AOR, adjusted odds ratio. *Adjusted age, marital status, unit type (acute ward, ICU/OR/ER, chronic ward) and hospital type (medical center, regional/district, clinic/nursing home). ${ }^{\dagger} p$-value for $\mathrm{X}^{2}$-statistic in the crude analysis.

2 days off after their last night shift had a lower level of overcommitment than those who had only received 1 day off since their last night shift (Table 4).

After adjustment for age, marital status, hospital grade (three groups) and unit type (three groups), nurses who had worked overtime an average of 3 or more days per week during the previous 2 months had 2.65-fold (95\% CI: 1.40-5.27) (Table 3) and 4.17-fold (95\% CI: 2.20-8.22) (Table 4) higher risks of effort/ reward imbalance and overcommitment compared with those who had regular work hours. Finally, we found that participating in planning working hours and shift scheduling was negatively associated with the odds ratio of effort/reward imbalance and overcommitment. The nurses who had little or no participation in planning their work schedules had 4.0-fold (95\% CI: 2.25-7.25) and 2.32-fold (95\% CI: 1.31-4.19) higher risks of a high effort/reward imbalance and overcommitment than those who had a high level of participa- tion in planning their shift schedules (Tables 3 and 4).

\section{Discussion}

This study showed that nurses who worked rotating shifts apparently had increased risk of overcommitment compared with those who worked day/non-night shifts. Of the nurses who worked night shifts, however, those who had received 2 days off after their last night shift and those who had a low frequency of 7 consecutive work days per month had low workrelated stress levels. Additionally, a heavy workload, which was defined as 3 or more days of overtime per week during the preceding 2 months, was associated with aggravated psychosocial occupational stress.

Overall, 32.6 and $48.3 \%$ of the nurses reported having experienced effort/reward imbalance and overcommitment, respectively. This is different from studies performed in other countries. For example, Sakata et $a l .^{3)}$ reported that 12.2 and $44.4 \%$ of medical resi- 
Table 4. Adjusted odds ratio (AOR) of overcommitment in the ERI model under the rotating shift arrangement among 414 nurses working rotating shifts

\begin{tabular}{|c|c|c|c|c|c|}
\hline & \multicolumn{5}{|c|}{ Overcommitment } \\
\hline & $\begin{array}{l}\text { Low } \\
\mathrm{N}(\%)\end{array}$ & $\begin{array}{l}\text { High } \\
\mathrm{N}(\%)\end{array}$ & $p$-value ${ }^{\dagger}$ & OR & AOR* \\
\hline Frequency of shift change & & & 0.8115 & & \\
\hline$<$ l week & $109(47.0)$ & $123(53.0)$ & & 1 & 1 \\
\hline 1 week to $<1$ month & $45(50.6)$ & $44(49.4)$ & & $0.87(0.53-1.41)$ & $0.84(0.50-1.40)$ \\
\hline$\geq 1$ month & $43(46.2)$ & $50(53.8)$ & & $1.03(0.64-1.67)$ & $0.94(0.56-1.60)$ \\
\hline Cumulative night shift days & & & 0.6072 & & \\
\hline 0 to $<7$ days & $81(45.0)$ & $99(55.0)$ & & 1 & 1 \\
\hline 7 to 14 days & $63(48.5)$ & $67(51.5)$ & & $0.87(0.55-1.37)$ & $0.93(0.58-1.49)$ \\
\hline$>14$ days & $53(51.0)$ & $51(49.0)$ & & $0.79(0.48-1.28)$ & $0.79(0.47-1.33)$ \\
\hline Days off after the last night shift & & & 0.0124 & & \\
\hline 1 day & $137(44.1)$ & $174(56.0)$ & & 1 & 1 \\
\hline 2 days & $60(58.3)$ & $43(41.8)$ & & $0.56(0.36-0.88)$ & $0.52(0.32-0.82)$ \\
\hline 7 consecutive work days & & & 0.0740 & & \\
\hline No & $125(63.5)$ & $120(55.6)$ & & 1 & 1 \\
\hline$<1$ time/month & $32(16.2)$ & $31(14.4)$ & & $1.01(0.58-1.76)$ & $0.91(0.51-1.63)$ \\
\hline at least 1 time/month & $40(20.3)$ & $65(30.1)$ & & $1.69(1.07-2.71)$ & $1.89(1.16-3.12)$ \\
\hline Overtime/week & & & $<0.0001$ & & \\
\hline None & $42(72.4)$ & $16(27.6)$ & & 1 & 1 \\
\hline$<3$ days/week & $65(56.0)$ & $51(44.0)$ & & $2.06(1.06-4.16)$ & $2.13(1.07-4.37)$ \\
\hline$\geq 3$ days/week & $90(37.5)$ & $150(62.5)$ & & $4.37(2.37-8.44)$ & $4.17(2.20-8.22)$ \\
\hline $\begin{array}{l}\text { Participation in planning } \\
\text { working hours and scheduling }\end{array}$ & & & 0.0147 & & \\
\hline High & $70(55.6)$ & $56(44.4)$ & & 1 & 1 \\
\hline Moderate & $95(48.0)$ & $103(52.0)$ & & $1.36(0.87-2.13)$ & $1.34(0.84-2.14)$ \\
\hline None to low & $32(35.6)$ & $58(64.4)$ & & $2.27(1.31-3.98)$ & $2.32(1.31-4.19)$ \\
\hline
\end{tabular}

OR, odds ratio; AOR, adjusted odds ratio. *Adjusted age, marital status, unit type (acute ward, ICU/OR/ER, chronic ward) and hospital type (medical center, regional/district, clinic/nursing home). ${ }^{\dagger} p$-value for $\mathrm{X}^{2}$-statistic in the crude analysis.

dents in Japan experienced effort/reward imbalance and overcommitment, whereas Conway et al..$^{8)}$ reported that 16.1 and $26.3 \%$ of health-care workers in Italy experienced effort/reward imbalance and overcommitment. A survey of a group of nurses in the ORSOSA study in France identified effort/reward imbalance in $10.7 \%$ of the nurses and overcommitment in $40.8 \%$ of the nurses ${ }^{19}$. Comparisons of the results of the current study with earlier studies of other occupations in Taiwan show effort/reward ratios of $0.74(0.22)$ and $0.97(0.34)$ in litigious lawyers and healthy engineers, respectively ${ }^{2,20)}$. However, the survey of engineers showed a mean overcommitment score of $14.5 \pm 5.2^{2)}$. In the current study, nurses who worked rotating shifts had a worse mean effort/reward ratio $(0.99 \pm 0.47)$ and overcommitment level $(16.7 \pm 2.84)$.

Selye ${ }^{21)}$ defined stress as "a state manifested by a syndrome which consists of all the nonspecifically induced changes in a biologic system". Since most humans follow a circadian rhythm, the peaks and troughs of which occur approximately over a 24-hour period, activity and rest tends to be synchronized with the rhythm. By interrupting the regular wake/sleep cycle, shift work can disturb circadian rhythms. This study revealed that nurses who work rotating shifts were most likely to have high overcommitment (OR: 2.16, 95\% CI: 1.03-4.66). The overcommitment component of the ERI model was intended to characterize the motivational pattern of excessive workrelated commitment, which is a coping mechanism that can have health effects such as emotional exhaustion. This finding suggested that that nurses working in a desynchronized environment might be less able to cope with the negative effects of the ERI model and shift work, and the night shift especially, could be a stressor for physiological system. However, our data were collected cross-sectionally, there is possibility that those with a tendency to experience overcom- 
mitment might be more likely to stay in a job that required working a night shift. Hence, the causal association should be further clarified.

In nurses who worked rotating shifts, high overcommitment was mildly attenuated by sufficient rest. The results of previous studies on sleep disturbance and fatigue, two common consequences of psychosocial stress, were consistent with the ERI model ${ }^{4,22)}$. A study of female critical care nurses also showed an association between poor sleep quality and fatigue ${ }^{23)}$. Because of the slow adjustment of circadian rhythm in rotating shift workers, several studies of workers ${ }^{24,25)}$, including nurses ${ }^{12,26)}$, have generally recommended 2 days off after the last night shift to attenuate sleep disturbances. The findings of this study also support the idea that work schedules of nurses should include 2 full days off after a night shift to ensure that they receive sufficient rest to avoid overcommitment.

Our findings also showed that effort/reward imbalance was significantly associated with the frequency of 7 consecutive work days. For a flexible rotating shift system, 5-7 consecutive work days are recommended $^{25)}$. The Labor Standards Act of Taiwan requires at least 1 regular day off for every 7 days, and 7 consecutive work days is lawful only under specified conditions. The empirical data obtained in this study confirm that this requirement is appropriate. For example, $25.4 \%$ of nurses who worked rotating shifts had had at least one series of 7 consecutive work days per month during the previous 2 months. Compared with nurses who worked other shift schedules, they also appeared to have a higher incidence of effort/reward imbalance, especially in terms of the reward component (reward scores: 37.4 on at least one series of 7 consecutive work days per month vs 42.3 for those who had not worked 7 consecutive work days per month). Hence, to attenuate work-related stress in nurses, an adequate number of nursing staff and an appropriate work schedule are needed to minimize the frequency of a high number of consecutive work days.

Another important observation was that, after adjusting for covariates, the risks of overcommitment and effort/reward imbalance correlated with the frequency of overtime per week. Overtime means prolonged exposure to work demands and is commonly characterized as exhibiting high demands and low control ${ }^{27,28)}$. Rogers et al. ${ }^{29)}$ examined over 5,300 shifts among a national sample of US nurses and found that $81 \%$ of those that had reached their scheduled end were lengthened. In this study, 58\% of nurses worked rotating shifts with overtime at least three times per week, and they were more likely to show overcommitment. Overtime is associated with high work stress, and may result in fatigue owing to the limited time available for recovery. Insufficient recovery has also been associated with various health problems or disorders ${ }^{30)}$. In addition, we found that the nurses who worked overtime at least three times per week tended to show effort/reward imbalance, particular in terms of the effort component, compared with nurses who did not work overtime (effort scores: 20.86 vs. 15.87). However, in the inflexible and high ratio of patient-to-nurse health-care system, the nurses had to work flexibly to deal with patient influxes or needs for extra assistance. However, no further information about hours of overtime per shift was collected, and this limits our study with respect to exploration of the association between the total amount of overtime burden or extreme overtime burden, e.g, very long hour overtime and work stress.

This study also found that nurses who reported having little or no participation in planning of working hours and shift scheduling were more likely to have high overcommitment and effort/reward imbalance. Participation in planning of working hours and shift scheduling refers to the flexibility to arrange work schedules and the physical and psychological preparation to meet the demands of work. Hence, a mechanism is needed to enhance the participation of nurses in work scheduling in order to improve their life-work balance and to alleviate work-related stress.

Of the covariates analyzed in this study, overcommitment in nurses working rotating shifts was significantly different among nurses who worked in different hospital units. For example, in contrast with other studies $^{31)}$, this study found that overcommitment was more common in nurses who worked in acute wards than in those who worked an ICU/OR/ER. Previous works indicate that the communication problems between doctors and nurses are a major stressor for nurses in neonatal ICUs or general wards nurses ${ }^{32}$. One proposed solution was to provide educational programs to improve the effectiveness of employees, especially in terms of teamwork and communication ${ }^{33)}$. In Taiwan, patients are often accompanied by their families during their hospital stay. Hence, nurses in acute wards must be proficient not only in providing effective nursing care but also in efficiently coordinating communications and information among families, doctors and other health-care providers. In future studies, we will further investigate this interesting and important aspect of nursing.

\section{Limitation}

This study had several limitations. First, it had a cross-sectional study design, so we were unable to prove any chronobiological effects of work stressors. Another limitation is its low response rate, with only 799 subjects from 1,486 nurses responding to this 
study. Hence, we further compared whether there were differences between respondents and nonrespondents based on the first investigation, and we did not find any significant differences regarding age, mental health score and sleep quality between these two groups. This suggested the low response rate might limit the generalizability of this study, but it was unlikely to result in a significant impact on our findings concerning the association between rotating shift work and occupational stress.

\section{Conclusions}

In our study, we found that night shift may increase occupational stress. However, this association may be improved through appropriate shift work scheduling. At least 2 days off, avoidance of a schedule containing 7 consecutive work days and increased participation in arranging work shifts might be able to reduce work stress. Our findings provide empirical data that can be used to reduce work-related stress in nurses by adjusting their work shifts. We suggest that the evidence-based knowledge obtained in this study should be considered by nursing department managers when arranging work schedules and designing shift scheduling systems that alleviate work stress in nurses who work rotating shifts.

Acknowldgments: The authors thank the Kaohsiung City and County Nurses Association and Teaching \& Research Center at Kaohsiung Municipal Hsiao-Kang Hospital for assistance with administrative coordination. This study was financially supported by grants from the Institute of Occupational Safety and Health, Council of Labor (IOSH-96-M318), Kaohsiung Medical University Hospital (KMUH 102-2R58) and the National Science Council, Taiwan (NSC101-2314B-037-037-MY3).

\section{References}

1) Sluiter JK, de Croon EM, Meijman TF, FringsDresen MH. Need for recovery from work related fatigue and its role in the development and prediction of subjective health complaints. Occup Environ Med 2003; 60 (Suppl 1): i62-70.

2) Chen SW, Wang PC, Hsin PL, Oates A, Sun IW, Liu SI. Job stress models, depressive disorders and work performance of engineers in microelectronics industry. Int Arch Occup Environ Health 2011;84: 91-103.

3) Sakata Y, Wada K, Tsutsumi A, et al. Effort-reward imbalance and depression in Japanese medical residents. J Occup Health 2008; 50: 498-504.

4) Sembajwe G, Wahrendorf M, Siegrist J, et al. Effects of job strain on fatigue: cross-sectional and prospective views of the job content questionnaire and effort--reward imbalance in the GAZEL cohort.
Occup Environ Med 2012; 69: 377-84.

5) Fang J, Kunaviktikul W, Olson K, Chontawan R, Kaewthummanukul T. Factors influencing fatigue in Chinese nurses. Nurs Health Sci 2008; 10: 291-9.

6) Taylor SE. Stress. Health Psychology. McGraw Hill International Edition ed. New York: McGraw Hill; 2009. p. 146-53.

7) Brown DL, Feskanich D, Sanchez BN, Rexrode KM, Schernhammer ES, Lisabeth LD. Rotating night shift work and the risk of ischemic stroke. Am J Epidemiol 2009; 169: 1370-7.

8) Conway PM, Campanini P, Sartori S, Dotti R, Costa G. Main and interactive effects of shiftwork, age and work stress on health in an Italian sample of healthcare workers. Appl Ergon 2008; 39: 630-9.

9) Jennings BM. Work stress and burnout among nurses: role of the work environment and working conditions. 2008 (Abstract).

10) Tanaka K, Otsubo T, Tanaka M, et al. Similarity in predictors between near miss and adverse event among Japanese nurses working at teaching hospitals. Ind Health 2010; 48: 775-82.

11) Maggie L. The dark moment of nurses in Taiwan. [Online]. 2012 [cited 2012 Apr 15]; Available from: URL: http://ireport.cnn.com/docs/DOC-776292.

12) Lin PC, Chen $\mathrm{CH}$, Pan SM, et al. Atypical work schedules are associated with poor sleep quality and mental health in Taiwan female nurses. Int Arch Occup Environ Health 2012; 85: 877-84.

13) Siegrist J, Peter R, Junge A, Cremer P, Seidel D. Low status control, high effort at work and ischemic heart disease: prospective evidence from blue-collar men. Soc Sci Med 1990; 31: 1127-34.

14) Siegrist J. Adverse health effects of high-effort/ low-reward conditions. J Occup Health Psychol 1996; 1: 27-41.

15) Tsutsumi A, Kawakami N. A review of empirical studies on the model of effort-reward imbalance at work: reducing occupational stress by implementing a new theory. Soc Sci Med 2004; 59: 2335-59.

16) Tseng $\mathrm{H}$, Cheng Y. Reliability and validity of the Chinese demand-control-support model and effortreward imbalance model questionnaires: a study among employees of microelectionics industry. Taiwan J Public Health 2002; 21: 420-32.

17) Siegrist J, Starke D, Chandola $T$, et al. The measurement of effort-reward imbalance at work: European comparisons. Soc Sci Med 2004; 58: 1483-99.

18) Li J, Yang W, Cheng Y, Siegrist J, Cho SI. Effortreward imbalance at work and job dissatisfaction in Chinese healthcare workers: a validation study. Int Arch Occup Environ Health 2005; 78: 198-204.

19) Herin F, Paris C, Levant A, Vignaud MC, Sobaszek A, Soulat JM. Links between nurses' organisational work environment and upper limb musculoskeletal symptoms: independently of effort-reward imbalance! The ORSOSA study. Pain 2011; 152: 2006-15.

20) Tsai FJ, Huang WL, Chan CC. Occupational stress 
and burnout of lawyers. J Occup Health 2009; 51: 443-50.

21) Selye H. The Stress of Life New York: McGrawHill; 1976.

22) Fahlen G, Knutsson A, Peter R, et al. Effort-reward imbalance, sleep disturbances and fatigue. Int Arch Occup Environ Health 2006; 79: 371-8.

23) Ruggiero JS. Correlates of fatigue in critical care nurses. Res Nurs Health 2003; 26: 434-44.

24) Rosa RR, Colligan MJ. Plain Language About Shiftwork. In: Public Health Service CfDCaP, editor.1997. p. 1-47.

25) Knauth P, Hornberger S. Preventive and compensatory measures for shift workers. Occup Med (Lond) 2003; 53: 109-16.

26) Berger AM, Hobbs BB. Impact of shift work on the health and safety of nurses and patients. Clin $\mathbf{J}$ Oncol Nurs 2006; 10: 465-71.

27) van der Hulst $M$, van Veldhoven $M$, Beckers D. Overtime and need for recovery in relation to job demands and job control. J Occup Health 2006; 48: 11-9.

28) Umehara K, Ohya Y, Kawakami N, Tsutsumi A,
Fujimura M. Association of work-related factors with psychosocial job stressors and psychosomatic symptoms among Japanese pediatricians. J Occup Health 2007; 49: 467-81.

29) Rogers AE, Hwang WT, Scott LD, Aiken LH, Dinges DF. The working hours of hospital staff nurses and patient safety. Health Aff (Millwood) 2004; 23: 202-12.

30) Geurts SA, Sonnentag S. Recovery as an explanatory mechanism in the relation between acute stress reactions and chronic health impairment. Scand J Work Environ Health 2006; 32: 482-92.

31) Lim J, Bogossian F, Ahern K. Stress and coping in Singaporean nurses: a literature review. Nurs Health Sci 2010; 12: 251-8.

32) Oates PR, Oates RK. Stress and work relationships in the neonatal intensive care unit: are they worse than in the wards? J Paediatr Child Health 1996; 32: 57-9.

33) Hamaideh SH, Ammouri A. Comparing Jordanian nurses' job stressors in stressful and non stressful clinical areas. Contemp Nurse 2011; 37: 173-87. 